University of Wollongong

Research Online

Faculty of Engineering - Papers (Archive)

Faculty of Engineering and Information

Sciences

1999

\title{
Carbon nanotube actuators
}

R. H. Baughman

Allied Signal, USA

C. X. Cui

Allied Signal, USA

A. A. Zakhidov

Allied Signal, USA

Z. Iqbal

Allied Signal, USA

J. N. Barisci

University of Wollongong

See next page for additional authors

Follow this and additional works at: https://ro.uow.edu.au/engpapers

Part of the Engineering Commons

https://ro.uow.edu.au/engpapers/495

\section{Recommended Citation}

Baughman, R. H.; Cui, C. X.; Zakhidov, A. A.; Iqbal, Z.; Barisci, J. N.; Spinks, Geoffrey M.; Wallace, G G.; Mazzoldi, A.; de Rossi, D.; Rinzler, A. G.; Jaschinski, O.; Roth, S.; and Kertesz, M.: Carbon nanotube actuators 1999.

https://ro.uow.edu.au/engpapers/495

Research Online is the open access institutional repository for the University of Wollongong. For further information contact the UOW Library: research-pubs@uow.edu.au 


\section{Authors}

R. H. Baughman, C. X. Cui, A. A. Zakhidov, Z. Iqbal, J. N. Barisci, Geoffrey M. Spinks, G G. Wallace, A. Mazzoldi, D. de Rossi, A. G. Rinzler, O. Jaschinski, S. Roth, and M. Kertesz 


\title{
Carbon Nanotube Actuators
}

\author{
Ray H. Baughman, ${ }^{1^{\star}}$ Changxing Cui, ${ }^{1}$ Anvar A. Zakhidov, ${ }^{1}$ Zafar lqbal, ${ }^{1}$ Joseph \\ N. Barisci, ${ }^{2}$ Geoff M. Spinks, ${ }^{2}$ Gordon G. Wallace, ${ }^{2}$ Alberto Mazzoldi, ${ }^{3}$ Danilo \\ De Rossi, ${ }^{3}$ Andrew G. Rinzler, ${ }^{4}$ Oliver Jaschinski, ${ }^{5}$ Siegmar Roth, ${ }^{5}$ Miklos \\ Kertesz $^{6}$
}

\begin{abstract}
Electromechanical actuators based on sheets of single-walled carbon nanotubes were shown to generate higher stresses than natural muscle and higher strains than high-modulus ferroelectrics. Like natural muscles, the macroscopic actuators are assemblies of billions of individual nanoscale actuators. The actuation mechanism (quantum chemical-based expansion due to electrochemical double-layer charging) does not require ion intercalation, which limits the life and rate of faradaic conducting polymer actuators. Unlike conventional ferroelectric actuators, low operating voltages of a few volts generate large actuator strains. Predictions based on measurements suggest that actuators using optimized nanotube sheets may eventually provide substantially higher work densities per cycle than any previously known technology.

\footnotetext{
${ }^{1}$ Research and Technology, AlliedSignal, 101 Columbia Road, Morristown, NJ 07962-1021, USA.

2 Intelligent Polymer Research Institute, University of Wollongong, New South Wales 2522, Australia.

${ }^{3}$ School of Engineering, University of Pisa, Centro E. Piaggio, Via Diotisalvi, 2-56100 Pisa, Italy.

${ }^{4}$ Department of Physics, University of Florida, Gainesville FL 32611-8440, USA.

${ }^{5}$ Max Planck Institut für Festkoerperforschung, Heisenbergstrasse 1, D-70569 Stuttgart, Germany.

${ }^{6}$ Department of Chemistry, Georgetown University, Washington, DC 20057-1227, USA.
}

The direct conversion of electrical energy to mechanical energy through a material response is critically important for such diverse needs as robotics, optical fiber switches, optical displays, prosthetic devices, sonar projectors, and microscopic pumps. Ferroelectric and electrostrictive materials are especially useful for direct energy conversion. However, applications are restricted by the maximum allowable operation temperature, the need for high voltages, and limitations on the work density per cycle.

Conducting polymer actuators based on electrochemical dopant intercalation were proposed a decade ago (1) and have been pioneered in many different laboratories (2, 3). Faradaic processes for these batterylike devices involve solid-state dopant diffusion and structural changes that limit rate, cycle life, and energy conversion efficiencies.

The new actuators we describe here use carbon single-walled nanotube (SWNT) sheets (4) as electrolyte-filled electrodes of a supercapacitor. No dopant intercalation 
is required for device operation. Changing the applied voltage injects electronic charge into a SWNT electrode, which is compensated at the nanotube-electrolyte interface by electrolyte ions (forming the so-called double layer). The new actuators use dimensional changes in covalently bonded directions caused by this charge injection, which originate from quantum chemical and double-layer electrostatic effects. For low charge densities, calculations (5) and experimental results (6) for charge transfer complexes of graphite and conducting polymers (Fig. 1) show that the strain due to quantum mechanical effects (changes in orbital occupation and band structure) changes sign from an expansion for electron injection to a contraction for hole injection. However, expansion results from both quantum chemical effects and electrostatic double-layer charging for high-density charge injection of either sign (5, $6)$.

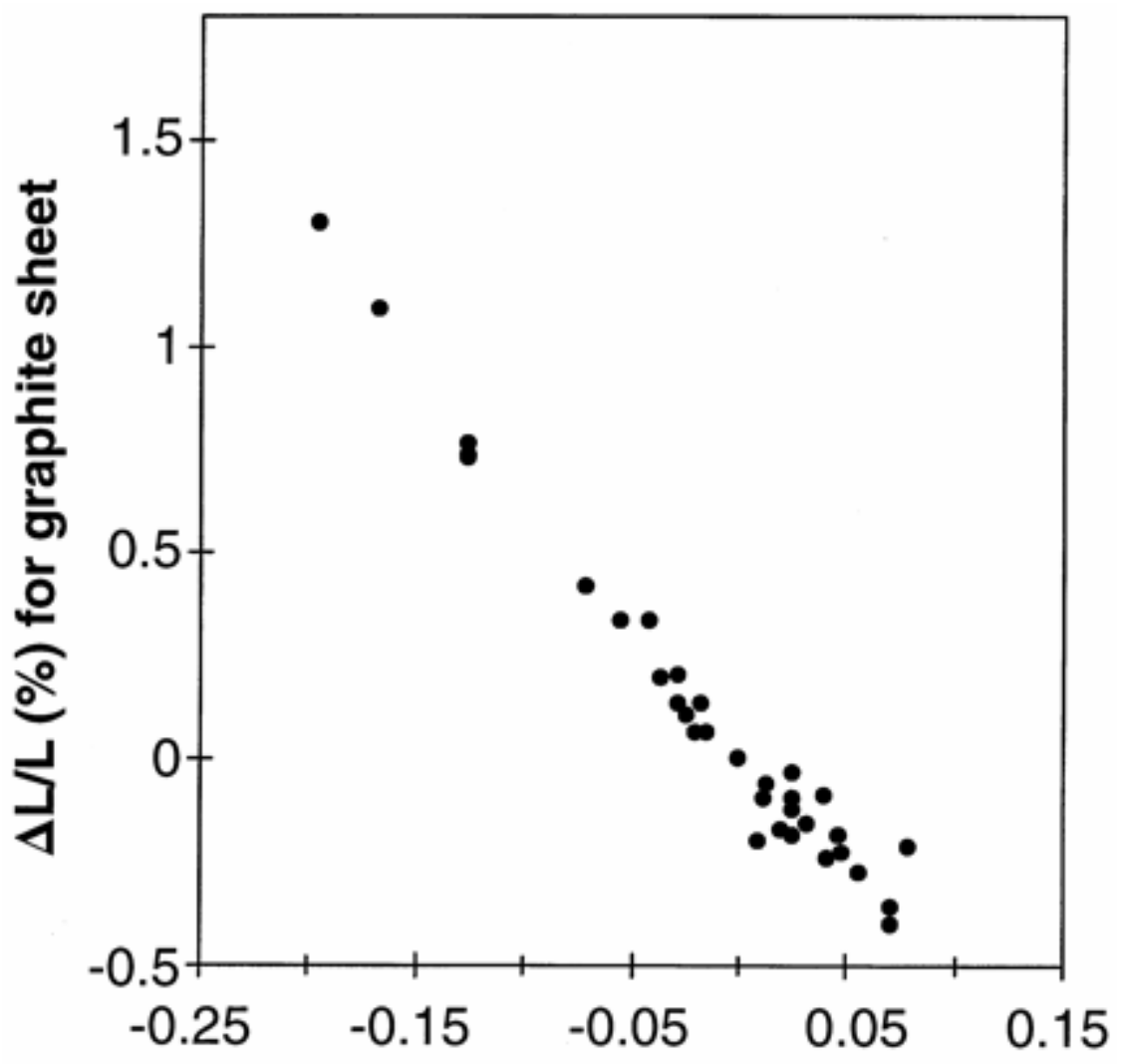

Nominal change per carbon

Fig. 1. Experimentally derived changes in basal plane strain as a function of nominal charge derived from data (6) for graphite intercalation compounds.

Like natural muscle (7), the nanotube sheet actuators are arrays of nanofiber actuators. A novel type of actuation results because the SWNTs add high surface area to the mechanical properties, electrical conductivity, and charge transfer properties of graphite. The results presented here are for nanotube sheets ("nanotube paper") composed of mats of nanotube bundles joined by mechanical entanglement and van der Waals forces along incidental points (and lines) of contact. These observations enable prediction of the actuator properties that are ultimately obtainable for 
nonbundled nanotubes, which have extraordinarily high surface area and mechanical properties (8). The concept of using either nanotube sheets or single nanotubes as actuators, and the effect of nanotube bundling, are schematically illustrated in Fig. 2.
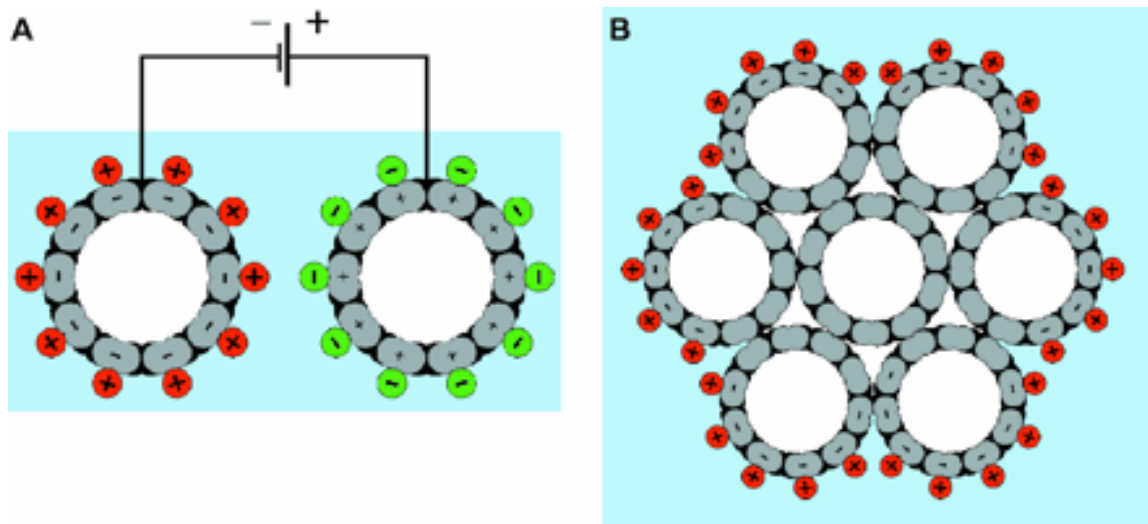

Fig. 2. Schematic illustration of charge injection in a nanotube-based electromechanical actuator and the effect of nanotube bundling. (A) An applied potential injects charge of opposite sign in the two pictured nanotube electrodes, which are in a liquid or solid electrolyte (blue background). These indicated charges in each electrode are completely balanced by ions from the electrolyte (denoted by the charged spheres on each nanotube cylinder). The pictured single nanotube electrodes represent an arbitrary number of nanotubes in each electrode that mechanically and electrically act in parallel. Depending on the potential and the relative number of nanotubes in each electrode, the opposite electrodes can provide either in-phase or out-of-phase mechanical deformations. (B) Charge injection at the surface of a nanotube bundle is illustrated, which is balanced by the pictured surface layer of electrolyte cations. Although penetration of electrolyte and gases into interstitial sites and nanotube cores might occur for the investigated bundled nanotubes, this has no noticeable effect on the observed BET surface area (11) or the measured electrode capacitance.

The commercially obtained nanotubes were made by the dual pulsed-laser vaporization method and purified by a published method that involves nitric acid reflux, cycles of washing and centrifugation, and cross-flow filtration $(4,9)$. Materials made by this method consist of hexagonally packed bundles of carbon nanotubes that have diameters of 12 to $14 \AA$, an intertube separation within a bundle of $\sim 17 \AA$, an average bundle diameter of $\sim 100 \AA$, and lengths of many micrometers $(4,10)$. The nanotube sheets were formed by vacuum filtration of a nanotube suspension on a poly(tetrafluorethylene) filter, and the dried nanotube sheets were peeled from the filter $(4,9)$. These freestanding sheets (composed of highly entangled nanotube bundles) were used as they were obtained, without any effort to optimize the mechanical properties, surface area, or electrical conductivity that are important for the actuator application.

The electrochemical charge injection process was characterized by measurement of the gravimetric capacitance $\left(C_{\mathrm{G}}\right)$ of the nanotube paper in various electrolytes [all 
potentials are versus a saturated calomel electrode (SCE)]. $C_{G}$ was derived from the slope of specific current versus voltage scan rate in a cell containing nanotube paper for both a working electrode and a counterelectrode. After a few cycles to ensure the maximum degree of electrode wetting, the measured $C_{\mathrm{G}}$ increased up to about $15 \mathrm{~F} / \mathrm{g}$ for aqueous solutions of both $1 \mathrm{M} \mathrm{NaCl}$ and $38 \%$ by weight $\mathrm{H}_{2} \mathrm{SO}_{4}$. Similar $C_{\mathrm{G}} \mathrm{S}$ were observed for $1 \mathrm{M} \mathrm{LiClO}_{4}$ in acetonitrile $(12$ to $17 \mathrm{~F} / \mathrm{g}$ ) or in propylene carbonate (13 to $14 \mathrm{~F} / \mathrm{g}$ ), and a higher $C_{\mathrm{G}}$ was observed for a $5 \mathrm{M}$ aqueous $\mathrm{KOH}$ solution $(30 \mathrm{~F} / \mathrm{g})$, which readily wet the nanotube paper.

These measurements and estimates of the available surface area suggest that double-layer charge injection for the nanotube bundles is similar to that for the basal plane of graphite. The gravimetric surface area of the nanotube paper $\left(A_{\mathrm{G}}\right)$ measured by the Brunauer-Emmett-Teller (BET) method is about $285 \mathrm{~m}^{2} / \mathrm{g} \mathrm{(11)}$; this value is near the $300 \mathrm{~m}^{2} / \mathrm{g}$ surface area of $100 \AA$ diameter cylinders having the crystallographically derived bundle density of $1.33 \mathrm{~g} / \mathrm{cm}^{3}(10)$, which suggests that the $\mathrm{N}_{2}$ in the BET measurement does not access significant surface area in the space between nanotubes in a bundle. An areal capacitance $\left(C_{A}\right)$ of 4 to $10 \mu \mathrm{F} / \mathrm{cm}^{2}$ results for the above range of observed gravimetric capacitances and an $A_{G}$ of $300 \mathrm{~m}^{2} / \mathrm{g}$. This value is in the approximate range of measured $C_{A} S$ for the basal plane of graphite (12), which has a minimum at $\sim 3 \mu \mathrm{F} / \mathrm{cm}^{2}$ (for either $0.9 \mathrm{M}$ aqueous $\mathrm{NaF}$ or $0.2 \mathrm{M}$ tetrapropylammonium tetrafluoride solution in acetonitrile).

Our first demonstration of a carbon nanotube actuator was surprisingly simple to produce. Similar to a design for a polyaniline conducting polymer actuator (3) (Fig. 3), this actuator consisted of cut strips of nanotube paper $(3 \mathrm{~mm}$ by $20 \mathrm{~mm}$ and 25 to $50 \mu \mathrm{m}$ thick) that were adhesively applied to opposite sides of a 10\% larger piece of Scotch Double Stick Tape. An insulating plastic clamp at the upper end of the threelayer strip supported the device vertically in $1 \mathrm{M} \mathrm{NaCl}$ electrolyte and held two platinum foil electrical leads in contact with the nanotube paper sheets. When a dc potential of a few volts or less was applied to these leads, a deflection of up to about a centimeter was observed for the cantilever tip, which reversed on reversal of the potential (Fig. 3). When a square wave potential was applied, oscillation was visually observed up to at least $15 \mathrm{~Hz}$ as the actuator pushed the electrolyte back and forth. Similar operation was observed for this type of actuator made from nanotube paper that had been annealed at $1100^{\circ} \mathrm{C}$ for 1 hour in flowing argon. 

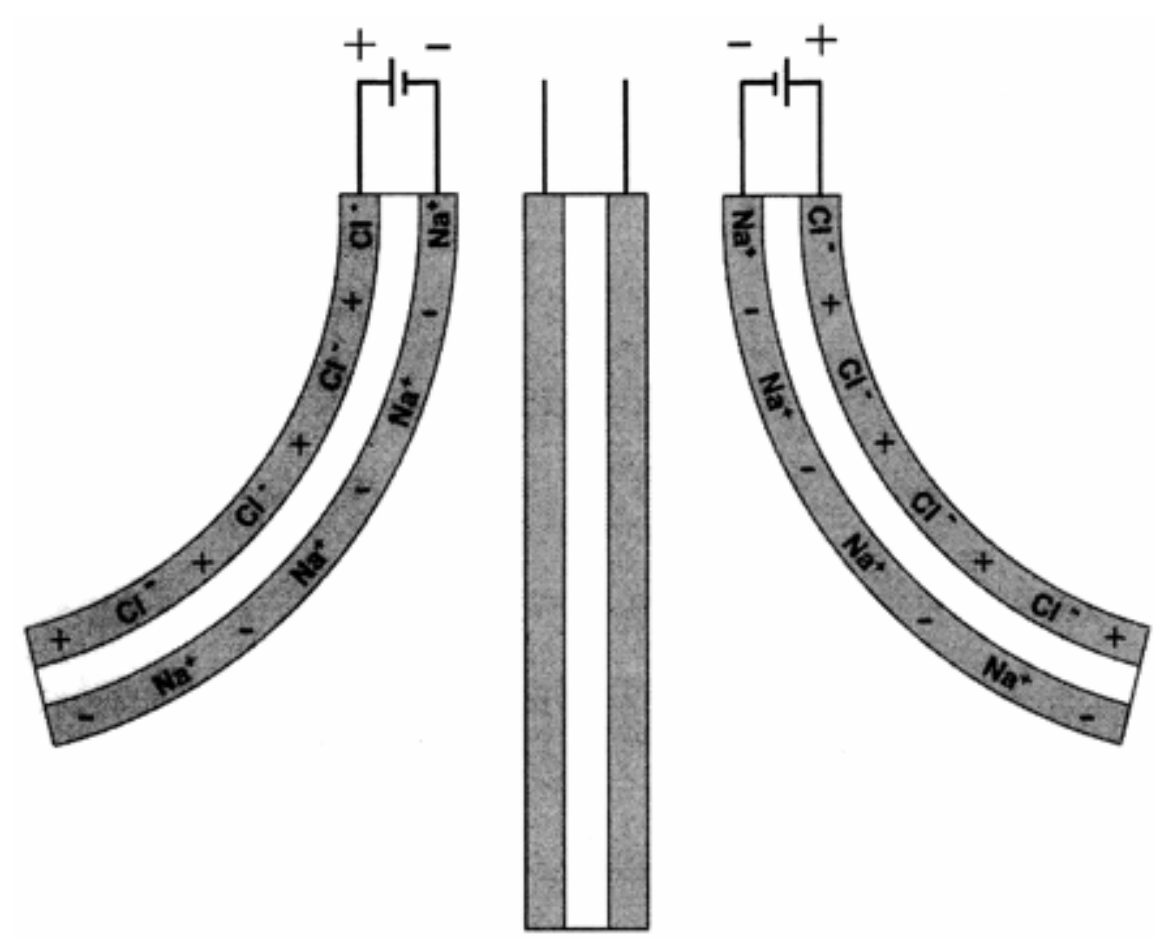

Fig. 3. Schematic edge-view of a cantilever-based actuator operated in aqueous $\mathrm{NaCl}$, which consists of two strips of SWNTs (shaded) that are laminated together with an intermediate layer of double-sided Scotch tape (white). The $\mathrm{Na}^{+}$and $\mathrm{Cl}^{-}$ions in the nanotube sheets represent ions in the double layer at the nanotube bundle surfaces, which are compensated by the indicated charges that are injected into the nanotube bundles. The equality between the lengths of the two nanotube sheets (center) is disrupted when a voltage is applied, causing the indicated actuator displacements to the left or right. The possible existence of a small amount of double-layer charge before the application of a voltage is ignored.

The above actuator is called a bimorph cantilever actuator because the device response depends on the difference in the electrically induced expansion of opposite actuator electrodes. In order to obtain more quantitative results, we made a bimorph cantilever actuator in which two nanotube sheets having the above strip dimensions worked to bend a strip of poly(vinylchloride) (PVC) film that was an order of magnitude thicker $(215 \mu \mathrm{m}$ thick) (Fig. 4A). This thick film (10\% wider and $20 \%$ longer than the nanotube paper strips) was laminated on both sides with nanotube paper strips by means of an intermediary layer of Scotch Double Stick Tape. The lower end of the actuator (containing the nanotube paper strips) was mounted in the bottom of the electrolyte bath $(1 \mathrm{M} \mathrm{NaCl})$ with a clamp that provided electrical contacts. The PVC strip from the actuator core extended above the electrolyte and supported a sputtered gold mirror on one strip face. The movement of this mirror as a result of actuator tip displacement was measured as a function of electrode potential with a Fotonic sensor from MTI Instruments. The actuator response was approximately linear, with applied voltage between -0.4 and $0.1 \mathrm{~V}$ (with negligible hysteresis) (Fig. 5), but both a nonlinear voltage dependence of displacement on potential and hysteretic behavior occurred at higher potentials. This actuator has a resonance peak at $25 \mathrm{~Hz}$ when 
driven in the liquid electrolyte with an ac voltage ( $2 \mathrm{~V}$ from peak to peak between the working electrode and the counterelectrode).

A

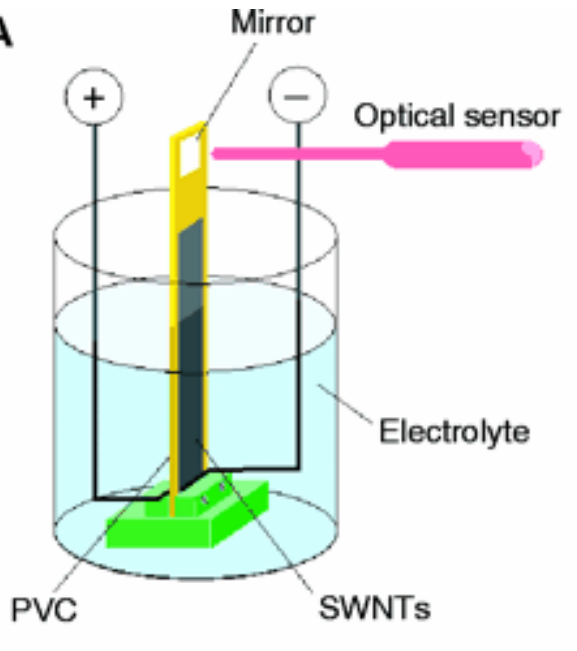

B

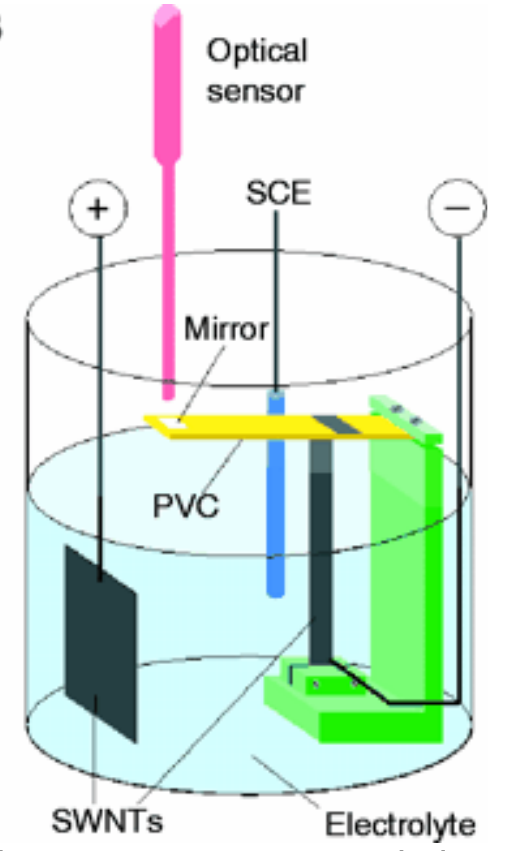

Fig. 4. (A) The apparatus used for characterizing an actuator, consisting of strips of SWNT paper that are symmetrically laminated (with an intermediate layer of doublesided Scotch tape) on opposite sides of a strip of PVC. Differential changes in the lengths of the nanotube strips bend the actuator, thereby causing a displacement of the mirror (which is measured with the optical sensor). Potentials were measured versus a reference SCE, which is not pictured. (B) The apparatus used for the measurement of the dependence of SWNT sheet length on applied potential (versus a SCE). Changes in the length of the nanotube strip bend the PVC cantilever that carries an attached mirror, whose displacement is measured with the optical sensor. 


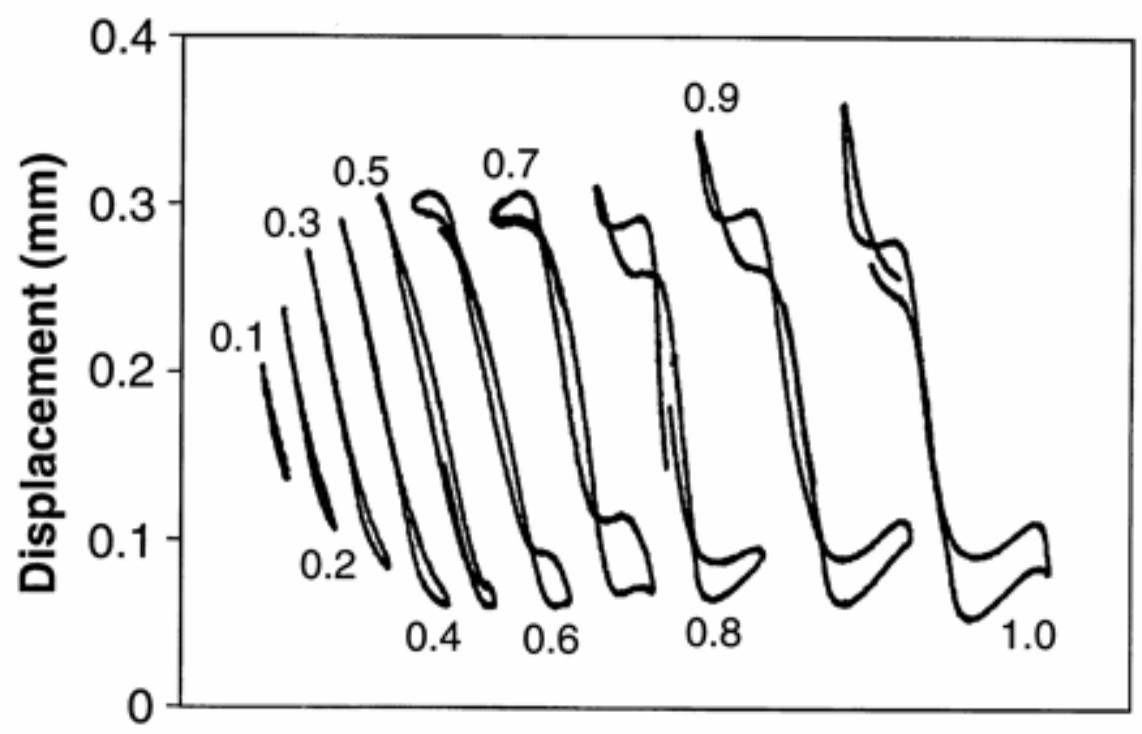

\section{Applied potential (V vs. SCE)}

Fig. 5. Measured cantilever displacement (arbitrary origin) versus electrode potential (in $1 \mathrm{M} \mathrm{NaCl}$ ) for a cantilever bimorph (Fig. 4A) in which two $15-\mu \mathrm{m}$-thick nanotube paper films bend a $215-\mu \mathrm{m}$-thick film of PVC. The potential range was symmetric about $0 \mathrm{~V}$ (versus a SCE), and the scan rate was $50 \mathrm{mV} / \mathrm{s}$. The labels on the curves indicate the maximum applied potential.

Because the response of the above bimorph cantilever actuators depends on the difference in the electrically induced expansion of opposite actuator electrodes, characterization of these devices does not directly provide the electromechanical response of the nanotube paper. Thus, we directly measured the change in length of the nanotube paper versus the potential in $1 \mathrm{M} \mathrm{NaCl}$. One end of a vertical nanotube paper strip was anchored to the bottom of the electrolyte bath, and the other end was attached to a horizontal cantilever (Fig. 4B). Changes in the length of the nanotube paper strip deflected the cantilever, whose movement was measured with an attached mirror and the above optical sensor. Like the field dependence for ferroelectrics, plots of deformation versus potential (Fig. 6A) show increasing hysteresis with increasing potential range during cyclic voltametry. The direction of strain change reverses at $0.56 \mathrm{~V}$ when potential is increased and at $0.27 \mathrm{~V}$ when potential is decreased for the highest voltage scan. Figure 6, B and C, show that the actuator devices can be effectively switched in $1 \mathrm{~s}$. Figure $6 \mathrm{C}$ shows that an actuator response, albeit small, can be observed to $>1 \mathrm{kHz}$. Cycling a strip of nanotube paper at a constant scan rate for 140,000 cycles (between $\pm 0.5 \mathrm{~V}$ at $1 \mathrm{~Hz}$ ) resulted in a $\sim 33 \%$ decrease in actuator stroke. A stress $(0.75 \mathrm{MPa})$ significantly higher than the peak capacity of human skeletal muscle $(0.3 \mathrm{MPa})$ was generated during the isometric contraction of a nanotube sheet [using a $0.1-\mathrm{Hz}$ square well potential between -0.5 and $1.5 \mathrm{~V}$ and the measurement apparatus described by Della Santa et al. (2)]. 

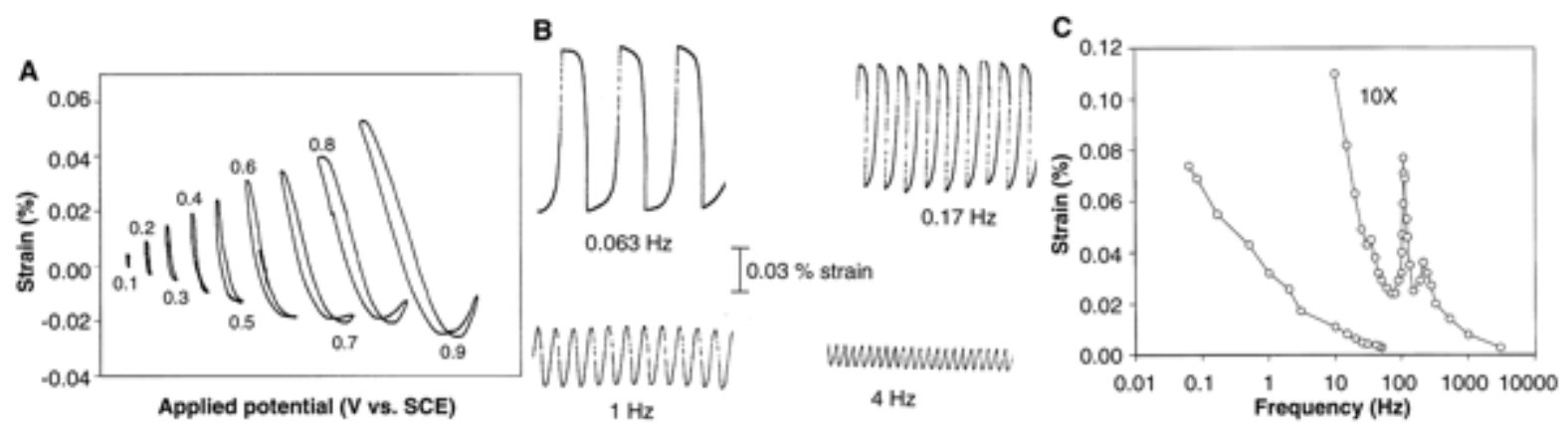

Fig. 6. Actuator characteristics measured by using the length changes of a nanotube sheet electrode to bend a cantilevered beam (Fig. 4B). Electrode potentials are versus a SCE for a $1 \mathrm{M}$ aqueous $\mathrm{NaCl}$ electrolyte. (A) The strain (arbitrary origin) of a nanotube sheet versus applied potential. The potential range was symmetric about $0 \mathrm{~V}$ (versus a SCE), and the scan rate was $100 \mathrm{mV} / \mathrm{s}$. The labels on the curves indicate the maximum applied potential. (B) The time dependence of the strain in a nanotube sheet for an applied square wave potential of $\pm 0.5 \mathrm{~V}$ having the indicated frequencies. (C) The frequency dependence of strain in a nanotube sheet electrode for an applied square wave potential of $\pm 0.5 \mathrm{~V}$. The frequency dependence of strain at higher frequencies (where the strain scale is amplified 10-fold) show resonances arising from the cantilever beam.

The dependence of strain on potential for the nanotube sheets (Fig. 6A) is quasiparabolic, like that observed in electrocapillary measurements on electrodes of activated carbon and exfoliated graphite (12). This response is expected if surface energy changes due to double-layer charging provide the mechanical stresses that elongate the material. If electrostatic effects dominate, the electrode dimension would be a minimum at the potential of zero charge (pzc), and either positive or negative charge injection would result in approximately equivalent expansion. In contrast, the minimum length occurs for the nanotube paper at a much higher potential $(0.27 \mathrm{~V}$ for reduction and $0.56 \mathrm{~V}$ for oxidation) than the expected pzc for the $1 \mathrm{M} \mathrm{NaCl}$ solution [about $-0.2 \mathrm{~V}$ versus a SCE, corresponding to the pzc for the basal plane of graphite (12)]. The implication is that quantum chemical effects are greater than classical coulombic effects for the carbon nanotube sheets. This result is consistent with the observation that the high-frequency tangential vibration mode of SWNTs increases frequency upon acceptor doping and decreases frequency upon donor doping (13), corresponding to bond shrinkage and expansion, respectively. Theory also predicts that quantum chemical effects dominate over electrostatic effects for charge transfer complexes of conducting polymers and graphite (5). This quantum chemical effect is large for metals having conjugated $\pi$ bonded backbones and is negligible for elemental metals.

Although nanotube bundling reduces strain, the maximum observed actuator strains are still large: $>0.2 \%$. The dimensional changes of the covalent bond network along the nanotube direction are the likely origin of these strains. Evidence that these observed changes in the sheet dimension are proportional to changes in the nanofiber length is provided by the observation of an in-plane thermal expansion coefficient that is an order of magnitude smaller than expected for a van der Waals bonded direction (14). 
The actuator response can be described by a strain-voltage coefficient $S_{V}$, which is the ratio of change in actuator strain to the change in applied electrode potential. The data in Fig. $6 \mathrm{~A}$ yield an $S_{\mathrm{V}}$ of $0.032 \% / \mathrm{V}$ in the potential range from -0.2 to $0.2 \mathrm{~V}$, which increases to $0.11 \% / \mathrm{V}$ in the nearly linear region between -0.8 and $-0.2 \mathrm{~V}$. Ignoring the dependence of observed specific capacitance on potential (which appears to be small), these $S_{V}$ values can be used to derive the strain-charge coefficient $(\Delta L / L \Delta y)$, where $\Delta L / L$ is the fractional change in length caused by a $\Lambda y$ change in the concentration of injected charge per monomer unit (1). The relation used is $S_{V}=C_{A} A_{G} M(\Delta L / L \Delta y) / N$, where $M$ is the monomer molecular weight and $N$ is the number of coulombs of charge in a mole of electrons. Using the observed gravimetric capacitance for a $1 \mathrm{M} \mathrm{NaCl}$ solution $\left(C_{\mathrm{G}}=C_{\mathrm{A}} A_{\mathrm{G}}=15 \mathrm{~F} / \mathrm{g}\right)$ and the above strain coefficients, the calculated $\Delta L L \Delta y$ increases from 0.17 (for -0.2 to $0.2 \mathrm{~V}$ ) to 0.59 (for 0.8 to $-0.2 \mathrm{~V}$ ). Even the former coefficient is greater than that derived for the basal plane of graphite from diffraction measurements on donor complexes $(0.066)(5,6)$. The existence of a larger strain-charge coefficient for SWNTs than for graphite is supported by the observation of greater stiffening of the tangential mode for SWNTs (relative to that for the graphite intralayer mode) upon acceptor doping (13).

We believe that only the nanotubes close to the bundle surface undergo substantial charging, so it is conceivable that these nanotubes elongate whereas the nanotubes in the bundle interior undergo little dimensional change. If different expansion of surface and interior nanotubes occurs, the above derived strain-charge coefficients would be upper bounds on the correct values. However, considering the very high aspect ratio of the nanotubes, it seems more likely that interfiber contact over long fiber distances will ensure that surface nanotubes and interior nanotubes undergo comparable elongations. In such a case, nonuniform charge distribution will affect the strainvoltage coefficient only to the extent that the strain-charge coefficient varies between differently charged regions of a nanotube bundle.

These results enable prediction of the actuator performance that may ultimately be obtained for separate (nonbundled) SWNTs. Isolated nanotubes having the observed van der Waals diameter of $17 \AA$ would have a surface area of $\sim 1600 \mathrm{~m}^{2} / \mathrm{g}$, which is about five times greater than for the investigated sheets consisting of nanotube bundles. If we use this surface area, the largest observed specific interfacial capacity $\left(10 \mu \mathrm{F} / \mathrm{cm}^{2}\right.$ for $\left.5 \mathrm{M} \mathrm{KOH}\right)$, and the strain-charge coefficient $(\Delta L / L \Delta y=0.59$ for -0.8 to $0.2 \mathrm{~V}$ ) derived with the $1 \mathrm{M} \mathrm{NaCl}$ electrolyte, we obtain $C_{\mathrm{G}}=160 \mathrm{~F} / \mathrm{gm}$ and $S=1.2 \% / \mathrm{V}$ for nanotube sheets composed of nonbundled nanotubes. The predicted maximum strain $\left(\varepsilon_{\mathrm{m}}\right)$ of $\sim 1 \%$ for operation in aqueous electrolytes (with a $1-\mathrm{V}$ operation range) and the substantially higher strain predicted for organic electrolytes are consistent with the $2 \%$ maximum variation in basal plane dimension that is observed for graphite intercalation compounds (Fig. 1). For comparison, presently used high-modulus ferroelectric ceramics provide a maximum strain of $\sim 0.1 \%$.

In addition to having a large displacement, a high-performance actuator material should have both high strength and high modulus. Based on theoretical and experimental results (15), a close-packed SWNT bundle composed of the investigated nanotubes should have a Young's modulus $(Y)$ of $\sim 0.64 \mathrm{TPa}\left(6.1 \times 10^{6} \mathrm{kgf} / \mathrm{cm}^{2}\right)$, which is more than two orders of magnitude greater than measured for our primitively constructed nanotube sheets $(\sim 1.2 \mathrm{GPa})$. The volumetric and gravimetric work densities per cycle for a matched mechanical load are proportional to $1 / 2 Y_{\varepsilon_{\mathrm{m}}}{ }^{2}$ and 
$1 / 2 \mathcal{E}_{\mathrm{m}}{ }^{2} / \rho$, respectively, where $\rho$ is the density $\left(1.33 \mathrm{~g} / \mathrm{cm}^{3}\right)$ of the nanotube bundles (16). The above extraordinarily high modulus inherent for the single nanotubes, combined with the above predicted actuator strain of $\sim 1 \%$, yield a predicted volumetric work capacity that is $\sim 29$ times higher than has been tabulated (16) for the best known ferroelectric, electrostrictive, and magnetostrictive materials. This predicted advantage of an ideal nanotube actuator increases to a factor of $\sim 150$ for gravimetric work capacity, which might be approached for nanoscale actuators based on separated nanotubes.

The origin of such spectacular predicted work capacities requires further explanation. As for ferroelectrics (17), the maximum work capacity per cycle is the product of the input electrical energy and a factor that increases from $\mathbf{k}^{2} / 4$ to $\mathbf{k}^{2} / 2$ with an increasing electromechanical coupling factor $\left(\mathbf{k}^{2}\right)$. Because $\mathbf{k}^{2}$ is the gravimetric ratio of stored mechanical energy to input electrical energy, the upper limit is approximately $\mathbf{k}^{2}=\left(1 / 2 S^{2} V^{2} Y / \rho\right) /\left(1 / 2 C_{\mathrm{G}} \mathrm{V}^{2}\right)=S^{2} Y / \rho C_{\mathrm{G}}$, which is linearly proportional to $A_{\mathrm{G}}$. If we use the above $S=1.2 \% / \mathrm{V}$ and $C_{\mathrm{G}}=160 \mathrm{~F} / \mathrm{gm}$ for separated nanotubes and the same $Y / \rho$ as for bundled nanotubes, $\mathbf{k}^{2}=0.43$, which is comparable to that of high-performance ferroelectrics (17). The giant predicted work capacities per cycle are almost entirely a consequence of the greater electrical energy storage densities as compared with those of ferroelectrics.

Even if the mechanical property optimization for sheets of nonbundled nanotubes results in a $Y / \rho$ value that is two orders of magnitude lower than experimentally derived (15) for individual nanotube bundles, the predicted gravimetric work capacity still exceeds that of any alternative actuator material. However, it must be emphasized that the present nanotube sheets are primitively constructed initial materials that are far from providing the surface areas and mechanical properties required for such predicted performance. Also, high power densities are required for many applications, and the presently achieved response rates of nanotube sheets are problematic for high-frequency applications. Additionally, although the observed 0.01-ms time constant of a micrometer-sized electrode (18) (having a large counterelectrode) suggests that very high-frequency operation may be achievable for single nanotube actuators, this remains to be experimentally demonstrated. Our nanotube actuators are first prototypes, and much more work is required before the potential advantages of this technology can be experimentally assessed in practical devices.

Nevertheless, relatively modest improvements in the presently demonstrated actuator properties may enable such applications as electrically activated microcantilevers for medical catheter applications, where a low operation voltage is a major advantage. Using high-temperature electrolytes (molten or solid state), it may be possible to make nanotube actuators that function at temperatures far above those usable for ferroelectrics, which might be important for such applications as aiflow control in jet engines. Also, demonstrations of nanotube actuator operation in seawater and in saline solutions, which are electrochemically like blood, suggest various possible marine and biomedical applications. Finally, nanotube actuators could be run in reverse to convert mechanical energy to electrical energy for mechanical sensor and energy-conversion devices. Ferroelectrics generate low currents at high voltages, but the nanotubes would provide high currents at low voltages. This effect is desirable for minimizing the effect of lead capacitances for remotely located sensors; for example, so that sensor-response amplifiers need not be located down-hole when doing 
seismology for oil exploration. If nanotubelike mechanical properties can be exploited to provide large inputs of mechanical energy, the output volumetric (or gravimetric) electrical energy per cycle would be much higher than that produced by alternative technologies. This feature, as well as the feasibility of operation at low frequencies, may eventually enable such applications as the conversion of the mechanical energy of ocean waves to electrical energy.

\section{REFERENCES AND NOTES}

1. R. H. Baughman, L. W. Shacklette, R. L. Elsenbaumer, E. J. Plichta, C. Becht, in Conjugated Polymeric Materials: Opportunities in Electronics, Optoelectronics, and Molecular Electronics, J. L. Bredas and R. R. Chance, Eds., vol. 182 of NATO ASI Series E: Applied Sciences (Kluwer, Dordrecht, Netherlands, 1990), pp. 559-582; R. H. Baughman, Synth. Met. 78, 339 (1996).

2. E. Smela, O. Inganäs, I. Lundström, Science 268, 1735 (1995); T. F. Otero and J. M. Sansinena, Adv. Mater. 10, 491 (1998); A. Della Santa, D. De Rossi, A. Mazzoldi, Smart Mater. Struct. 6, 23 (1997); M. R. Gandhi, P. Murray, G. M. Spinks, G. G. Wallace, Synth. Met. 73, 247 (1995); J. D. Madden, P. G. Madden, I. W. Hunter, S. R. Lafontaine, C. J. Brenan, in Proceedings-Workshop on Working in the Micro-World, IEEE IROS96, Osaka, Japan, November 1996 (IEEE, New York, 1996), pp. 9-18.

3. K. Kaneto, M. Kaneko, Y. Min, A. G. MacDiarmid, Synth. Met. 71, 2211 (1995).

4. J. Liu, et al., Science 280, 1253 (1998); A. G. Rinzler, et al., Appl. Phys. A 67, 29 (1998).

5. L. Pietronero and S. Strässler, Phys. Rev. Lett. 47, 593 (1981); M. Kertesz, Mol. Cryst. Liq. Cryst. 126, 103 (1985) ; C. T. Chan, W. A. Kamitakahara, K. M. Ho, P. C. Eklund, Phys. Rev. Lett. 58, 1528 (1987); R. H. Baughman, N. S. Murthy, H. Eckhardt, M. Kertesz, Phys. Rev. B 46, 10515 (1992).

6. D. E. Nixon and G. S. Perry, J. Phys. C Solid State Phys. 2, 1732 (1969); Y. Murakami, T. Kishimoto, H. Suematsu, J. Phys. Soc. Jpn. 59, 571 (1990); J. E. Fisher, H. J. Kim, V. B. Cajipe, Phys. Rev. B 36, 4449 (1987); W. A. Kamitakahara, J. L. Zaresky, P. C. Eklund, Synth. Met. 12, 301 (1985) ; F. Baron, S. Flandrois, C. Hauw, J. Gaultier, Solid State Commun. 42, 759 (1982); S. Flandrois, C. Hauw, R. B. Mathur, Synth. Met. 34, 399 (1990).

7. J. A. Spudich, Nature 372, 515 (1994).

8. E. W. Wong, P. E. Sheehan, C. M. Leber, Science 273, 1971 (1997) ; M. R. Falvo, et al., Nature 389, 582 (1997).

9. The SWNTs were commercially obtained as an aqueous suspension from Tubes@Rice (Rice Univ., Houston, TX). The nanotube sheets were typically made by vacuum filtration of $\sim 20 \mathrm{ml}$ of a $\sim 0.6 \mathrm{mg} / \mathrm{ml}$ nanotube suspension through a poly(tetrafluoroethylene) filter (Millipore LS, $47 \mathrm{~mm}$ in diameter, 5- $\mu \mathrm{m}$ pores). The nanotube sheet (formed over the clear funnel area, which was $37 \mathrm{~mm}$ in diameter) was washed with $\sim 200 \mathrm{ml}$ of deionized water and then $100 \mathrm{ml}$ of methanol to remove residual $\mathrm{NaOH}$ and surfactant, respectively. These sheets were allowed to dry under continued vacuum purge for $\sim 1$ hour before being peeled from the filter. The typical nanotube sheet was between 15 and $35 \mu \mathrm{m}$ thick and weighed $\sim 12 \mathrm{mg}$, providing a bulk density of 0.3 to $0.4 \mathrm{~g} / \mathrm{cm}^{3}$ and a four-point probe electrical conductivity of $\sim 5000 \mathrm{~S} / \mathrm{cm}$. 
10. A. Thess, et al., Science 273, 483 (1996).

11. Y. Ye, et al., Appl. Phys. Lett. 74, 2307 (1999).

12.J.-P. Radin and E. Yeager, Electroanal. Chem. Interfacial Electrochem. 36, 257 (1972) ; H. Gerischer, R. Mclntyre, D. Scherson, W. Storck, J. Phys. Chem. 91, 1930 (1987); Y. Oren, I. Glatt, A. Livnat, O. Kafri, A. Soffer, J. Electroanal. Chem. 187, 59 (1985).

13. A. M. Rao, P. C. Eklund, S. Bandow, A. Thess, R. E. Smalley, Nature 388, 257 (1997).

14. R. H. Baughman et al., unpublished data.

15. G. Gao, T. Çagin, W. A. Goddard, Nanotechnology 9, 184 (1998); M. M. J. Treacy, T. W. Ebbesen, J. M. Gibson, Nature 381, 678 (1996); E. W. Wong, P. E. Sheehan, C. M. Lieber, Science 277, 1971 (1997).

16. Q. M. Zhang, V. Bharti, X. Zhao, Science 280, 2101 (1998).

17. K. Uchino, Piezoelectric Actuators and Ultrasonic Motors (Kluwer Academic, Boston, 1997).

18. R. J. Forster, Chem. Soc. Rev. 23, 289 (1994).

19. We thank J. Su, W. Kuhn, V. Z. Vardeny, L. Dalton, R. Duran, L. Grigorian, and P. C. Eklund for discussions and other valuable contributions. Partially supported by Defense Advanced Research Projects Agency grant N00173-992000. 